\title{
Níveis de Lisina Digestível em Rações para Frangos de Corte de 1 a 21 Dias de Idade Mantidos em Ambiente de Termoneutralidade ${ }^{1}$
}

\author{
Sandra Roselí Valerio Lana², Rita Flávia Miranda de Oliveira ${ }^{3}$, Juarez Lopes Donzele ${ }^{3}$, Luiz \\ Fernando Teixeira Albino ${ }^{3}$, Roberta Gomes Marçal Vieira Vaz ${ }^{4}$, Wilkson de Oliveira Rezende ${ }^{5}$
}

\begin{abstract}
RESUMO - Dois ensaios foram conduzidos para avaliar rações com diferentes níveis de lisina digestível, mantendo-se ou não a relação aminoacídica, para frangos de corte de 1 a 21 dias, criados em ambiente de termoneutralidade. Em ambos os ensaios, utilizou-se o delineamento experimental inteiramente casualizado. No ensaio 1, os frangos foram distribuídos em cinco tratamentos (0,92; 0,98; 1,04; 1,10 e 1,16\% de lisina digestível, em ração convencional), oito repetições e dez aves por repetição, enquanto, no ensaio 2, foram distribuídos em quatro tratamentos $(1,04 ; 1,10 ; 1,16$ e 1,22\% de lisina digestível, em rações mantendo a relação aminoacídica), oito repetições e dez aves por repetição. No ensaio 1 , os tratamentos influenciaram o ganho de peso, o consumo de ração, que aumentaram de forma quadrática até os níveis de 1,13 e 1,11\%, respectivamente, e a conversão alimentar, que reduziu até o nível de 1,14\% de lisina. O peso absoluto da carcaça aumentou até o nível de 1,13\% de lisina digestível. O peso relativo da carcaça e o peso absoluto da moela aumentaram, enquanto os pesos relativos do coração e os dos intestinos reduziram linearmente com os tratamentos. No ensaio 2, apesar do ganho de peso ter elevado de forma linear, o modelo LRP foi o que melhor se ajustou aos dados, estimando em 1,17\% o nível de lisina, a partir do qual ocorreu um platô. Os tratamentos não influenciaram o consumo de ração, a conversão alimentar e os pesos absoluto e relativo dos órgãos, enquanto o peso absoluto de carcaça aumentou de forma linear. Concluiu-se que frangos de corte machos Avian Farm, no período de 1 a 21 dias, criados em ambiente de termoneutralidade, exigem no mínimo 1,14 e 1,17\% de lisina digestível em ração convencional e em ração mantendose a relação aminoacídica, respectivamente.
\end{abstract}

Palavras-chave: frangos de corte, lisina digestível, proteína ideal, termoneutralidade

\section{Requirements of Dietary Digestible Lysine for Broilers from 1 to 21 Days Old on Thermoneutral Environment}

\begin{abstract}
Two trials were conducted to evaluate the requirements of increasing dietary digestible lysine levels, maintaining or not the amino acids relation, for broilers from 1 to 21 days old, on thermoneutral environment. A complete randomized experimental design was used in both trials. In trial 1, broilers were allotted to five treatments $(0.92,0.98,1.04,1.10$, and 1.16\% digestible lysine levels, conventional diet), with eight replicates of ten birds. In trial 2, chicks were allotted to four treatments $(1.04,1.10,1.16$, and $1.22 \%$ of digestible lysine, in diets maintaining amino acid relation) with eight replicates of ten birds. In trial 1, effects of dietary lysine levels on body weight gain and feed intake, both increasing quadraticly up to 1.13 and $1.11 \%$ digestible lysine, respectively, were observed. There was significant treatment effect on feed:gain ratio, that decreased quadraticly up to $1.14 \%$ digestible lysine. Absolute carcass weight increased quadractily while relative carcass values and absolute weight of gizzard increased linearly with treatments. Relative weights of heart and intestines decreased linearly with the treatments. In trial 2, body weight gain also increased linearly with treatments, the LRP model better adjusted to data, where the 1.17\% digestible lysine level was estimated. No effects of treatments on feed intake and feed:gain ratio were detected. Absolute carcass weight was linearly affected by the increasing dietary lysine levels. There was no effect of dietary lysine levels on absolute and relative weights of all evaluated organs. It was concluded that Avian Farms male broilers, in the period from 1 to 21 days, require at least 1.14 and $1.17 \%$ digestible lysine, in a conventional diet or of a diet maintaining the amino acid relation, respectively, on a thermoneutral environment.
\end{abstract}

Key Words: broilers, digestible lysine, ideal protein, thermoneutrality

\section{Introdução}

A lisina, por ser considerada o segundo amninoácido limitante para frangos de corte, tem sua exigência largamente estudada. No entanto, diversos fatores influenciam a exigência de lisina, como estresse, linhagem, ambiente térmico, teor de proteína da ração, energia digestível e, principalmente, os alimentos utilizados na formulação das rações.

Atualmente, com o aumento da produção comercial de aminoácidos sintéticos e a tendência de elevação dos custos das fontes protéicas, tem sido crescente

\footnotetext{
1 Parte da tese de doutorado da primeira autora - Projeto financiado pela FAPEMIG.

2 Professora da UFAL.

3 Professor do DZO/UFV. E.mail: flavia@ufv.br; donzele@ufv.br

4 Estudante Pós-graduação DZO/UFV. E.mail: robertavaz@lycos.com

${ }^{5}$ Secretaria de Agricultura - Cuiabá - MT.
} 
a inclusão de aminoácidos sintéticos às rações, permitindo reduzir os teores de proteína bruta em níveis abaixo do recomendado. Para uma proteína ser ideal, deve haver balanceamento exato dos aminoácidos, sem deficiência ou excesso, com o objetivo de satisfazer as exigências absolutas de todos os aminoácidos para mantença e ganho de proteína corporal máximo (Zaviezo, 1998).

A exigências dos aminoácidos pode ser estimada com base em um aminoácido referência, a lisina, que, embora seja o segundo aminoácido limitante, depois da metionina, foi escolhido principalmente porque, em seu metabolismo, é utilizado quase exclusivamente para acréscimo de proteína corporal (Pack, 1995).

A recomendação de lisina digestível em rações para frangos de corte na fase de 1 a 21 dias de idade varia de 1,063 a 1,143\% (Emmert \& Baker, 1997; Rostagno et al., 2000).

Avaliando a suplementação de aminoácidos sintéticos em rações para frangos de corte, Parr \& Summers (1991) observaram melhoria gradativa no ganho de peso, à medida que o balanço de aminoácidos das rações se aproximava do padrão de proteína ideal estabelecido para aquela categoria animal. Da mesma forma, Surisdiarto \& Farrel (1991) encontraram resultados positivos no desempenho das aves, quando avaliaram rações suplementadas com aminoácidos sintéticos, considerando o padrão de proteína ideal. Recentemente, Conhalato et al. (2000) e Cella et al. (2000), estudando os efeitos dos níveis de lisina digestível mantendo a relação da lisina com os aminoácidos metionina, isoleucina, treonina, triptofano, valina e arginina, para frangos de corte de 1 a 21 dias de idade, constataram que os níveis de 1,20 e 1,293\% de lisina digestível, respectivamente, propiciaram os melhores resultados de desempenho. Costa et al. (1999) recomendaram 1,27 e 1,16\% de lisina total e digestível para frangos de corte na fase de 1 a 21 dias de idade, respectivamente. Por outro lado, estudos realizados por Barboza et al. (2000) demonstraram que os frangos no período de 1 a 21 dias de idade exigiram $1,18 \%$ de lisina total em rações contendo $3.050 \mathrm{kcal}$ de EM/kg, desconsiderando-se o conceito de proteína ideal.

Este trabalho foi conduzido para se avaliarem níveis de lisina digestível em rações, mantendo ou não a relação aminoacídica, para frangos de corte machos de 1 a 21 dias de idade, criados sob condições de termoneutralidade.

\section{Material e Métodos}

Os ensaios foram conduzidos no Laboratório de Bioclimatologia Animal do Departamento de Zootecnia do Centro de Ciências Agrárias da Universidade Federal de Viçosa, em Viçosa, MG.

Ensaio 1 - Níveis de lisina digestível em rações convencionais para frangos de corte de 1 a 21 dias de idade, criados em ambiente de termoneutralidade

Foram utilizados 400 frangos de corte machos da linhagem Avian Farms, na fase de 1 a 21 dias de idade, com peso inicial de 47,9 g $\pm 0,21 \mathrm{~g}$, vacinados contra as doenças de Marek e Bouba aviária, mantidos em câmaras climáticas, sob temperatura e umidade relativa recomendados no manual da linhagem Avian Farms (Tabela 1).

Tabela 1 - Condições ambientais observadas nas câmaras climáticas durante o período experimental (recomendações Avian Farms) ${ }^{1}$

Table 1 - Environmental conditions observed in the climatic chambers during the experimental period for male broilers from 1 to 21 days old (Avian Frams recomendations) ${ }^{1}$

\begin{tabular}{ccccc}
\hline $\begin{array}{l}\text { Idade (dias) } \\
\text { Age (days) }\end{array}$ & $\begin{array}{c}\text { Temperatura do ar }\left({ }^{\circ} \mathrm{C}\right) \\
\text { Air temperature }\end{array}$ & $\begin{array}{c}\text { Umidade relativa }(\%) \\
\text { Relative humidity }\end{array}$ & $\begin{array}{c}\text { Temperatura de globo negro }\left({ }^{\circ} \mathrm{C}\right) \\
\text { Black globe temperature }\end{array}$ & $\begin{array}{c}\text { ITGU }^{2} \\
\text { BHGI }\end{array}$ \\
\hline 1 & $33,28 \pm 0,28$ & $50,0 \pm 0,82$ & $33,65 \pm 0,34$ & $81,58 \pm 0,18$ \\
2 & $32,16 \pm 0,13$ & $53,06 \pm 2,01$ & $32,34 \pm 0,07$ & $80,85 \pm 0,36$ \\
$3-4$ & $30,30 \pm 0,49$ & $53,16 \pm 2,57$ & $30,59 \pm 0,40$ & $78,69 \pm 0,62$ \\
$5-8$ & $29,46 \pm 0,89$ & $53,45 \pm 2,90$ & $29,76 \pm 0,71$ & $77,26 \pm 0,76$ \\
$9-11$ & $28,07 \pm 0,16$ & $59,10 \pm 3,12$ & $28,24 \pm 0,14$ & $76,22 \pm 0,24$ \\
$12-16$ & $27,35 \pm 0,41$ & $60,11 \pm 1,36$ & $27,59 \pm 0,44$ & $75,54 \pm 0,60$ \\
$17-21$ & $26,40 \pm 0,32$ & $60,85 \pm 1,01$ & $26,62 \pm 0,34$ & $74,73 \pm 0,49$ \\
\hline
\end{tabular}

1 Valores médios (Average values).

2 İndice de temperatura de globo e umidade (Black globe and humidity index). 
As aves foram alojadas em baterias metálicas, com $0,72 \mathrm{~m}^{2}$ de piso telado por compartimento, dotadas de comedouros e bebedouros tipo calha. O monitoramento de temperatura e umidade relativa do ar de cada sala foi feito por meio de termômetros de máxima e mínima, de bulbos seco e úmido e de globo negro, mantidos no centro da sala. As leituras dos termômetros foram realizadas diariamente, duas vezes ao dia (8 e 18h), durante todo o período experimental. O programa de luz adotado foi o contínuo (24 horas de luz artificial) durante todo período experimental, utilizando-se duas lâmpadas fluorescentes de 75 watts por sala. As aves foram distribuídas em delineamento inteiramente casualizado, com cinco tratamentos, oito repetições e dez aves por repetição.

Os tratamentos consistiram de uma ração basal (Tabela 2) à base de milho, farelo de soja e glúten de milho, formulada para atender às exigências das aves, segundo recomendações de Rostagno et al. (1996), exceto em lisina. A ração basal foi suplementada com L-lisina $99 \%(0,00 ; 0,06 ; 0,12 ; 0,18$ e 0,24$)$ em substituição ao caulim, resultando em rações experimentais contendo 1,04 e $0,92 \% ; 1,10$ e $0,98 \% ; 1,16$ e $1,04 \% ; 1,22$ e $1,10 \% ; 1,28$ e $1,16 \%$ de lisina total e digestível, respectivamente. Os valores de aminoácidos totais dos ingredientes da ração experimental foram obtidos por meio de análises laboratoriais e posteriormente corrigidos para aminoácidos digestíveis, utilizando-se os coeficientes de digestibilidade das tabelas Rhodimet-Rhône-Poulenc (1993) (Tabela 3). O fornecimento de ração e água foi ad libitum, trocando-se a água duas vezes ao dia.

As variáveis estudadas foram: consumo de ração, ganho de peso, conversão alimentar, consumo de lisina digestível e pesos absoluto (g) e relativo (\%) das carcaças inteiras, dos órgãos comestíveis (coração, fígado e moela) e não-comestíveis (intestinos).

No final do período experimental ( $21^{\circ} \mathrm{o}$ dia), as aves foram pesadas após jejum alimentar de 12 horas. Quatro aves de cada unidade experimental, com peso de $\pm 10 \%$, em relação a média da repetição, foram abatidas e, após o sangramento e a depena, evisceradas, tendo, posteriormente, suas carcaças pesadas.

Na determinação do rendimento de carcaça, foi considerado o peso da carcaça limpa em relação ao peso vivo após jejum. Os pesos relativos dos órgãos foram calculados em relação ao peso da carcaça eviscerada.

As análises estatísticas das variáveis estudadas foram realizadas utilizando-se o programa SAEG
Tabela 2 - Composição percentual da ração basal Table 2 - Composition (\%) of the basal diet

\begin{tabular}{|c|c|}
\hline Ingrediente (Ingredient) & $(\%)$ \\
\hline Milho (Corn) & 60,792 \\
\hline Farelo de soja (Soybean meal) & 27,826 \\
\hline Glúten de milho (Corn gluten) & 4,692 \\
\hline Fosfato bicálcico (Dicalcium phosphate) & 1,852 \\
\hline Calcário (Limestone) & 1,180 \\
\hline Óleo de soja (Soybean oil) & 1,343 \\
\hline Sal comum (Salt) & 0,404 \\
\hline 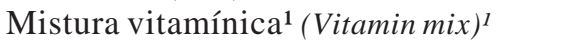 & 0,100 \\
\hline Mistura mineral $^{2}{\text { (Mineral mix })^{2}}^{2}$ & 0,050 \\
\hline Anticoccidiano $^{3}$ & 0,050 \\
\hline $\mathrm{BHT}^{4}$ & 0,010 \\
\hline Cloreto de colina ${ }^{5}$ (Coline chloride) ${ }^{5}$ & 0,125 \\
\hline Stafac $^{6}$ & 0,055 \\
\hline Caulin & 1,275 \\
\hline L-lisina (99\%) (L-lysine) & 0,000 \\
\hline DL-metionina (99\%) (DL-methionine) & 0,230 \\
\hline L-treonina $(98,5 \%)$ (L-threonine) & 0,011 \\
\hline L-triptofano (99\%) (L-tryptophan) & 0,005 \\
\hline \multicolumn{2}{|c|}{ Composição calculada (Calculated composition) } \\
\hline Proteína bruta (\%) (Crude protein) & 21,00 \\
\hline Energia metabolizável (kcal/kg) & 3.000 \\
\hline \multicolumn{2}{|l|}{ Metabolizable energy } \\
\hline Lisina total (\%) (Total lysine) & 1,04 \\
\hline Lisina digestível (\%) (Digestible lysine) & 0,92 \\
\hline Metionina + cistina digestível (\%) & 0,797 \\
\hline \multicolumn{2}{|l|}{ Digestible methionine + cystine } \\
\hline Treonina digestível (\%) & 0,662 \\
\hline \multicolumn{2}{|l|}{ Digestible threonine } \\
\hline Triptofano digestível (\%) & 0,181 \\
\hline \multicolumn{2}{|l|}{ Digestible tryptophan } \\
\hline Cálcio (Calcium) (\%) & 0,995 \\
\hline Fósforo disponível (\%) & 0,453 \\
\hline \multicolumn{2}{|l|}{ Available phosphorous } \\
\hline Sódio (\%) (Sodium) & 0,200 \\
\hline \multicolumn{2}{|c|}{$\begin{array}{l}{ }^{1} \text { Conteúdo/kg (Content/kg) - vit. A - } 15.000 .000 \mathrm{UI} \text {, vit. D3 - } \\
1.500 .000 \mathrm{Ul} \text {, vit. E - } 15.000 \mathrm{UI} \text {, vit. B1 - 2,0 g, vit. B2 - 4,0 g, vit. } \\
\text { B6 - 3,0 g, vit. B12 - 0,015 g, ácido nicotínico (nicotinic acid) - } 25 \mathrm{~g} \text {, } \\
\text { ácido pantotênico (pantothenic acid)- } 10 \mathrm{~g} \text {, vit. K3 - 3,0 g, ácido } \\
\text { fólico (folic acid)- } 1,0 \mathrm{~g} \text { bacitracina de zinco (zinc bacitracine) - } \\
10 \mathrm{~g} \text {, selênio (selenium) - } 250 \mathrm{mg} \text {, antioxidante BHT (antioxidant BHT) } \\
\text { - } 10 \mathrm{~g} \text { e veículo qsp - } 1.000 \mathrm{~g} \text {. } \\
{ }^{2} \text { Conteúdo/kg (Content/kg)-manganês (manganese), } 80 \mathrm{~g} \text {; ferro (iron), } \\
80 \mathrm{~g} \text {; zinco (zinc), } 50 \mathrm{~g} \text {; cobre (copper), } 10 \mathrm{~g} \text {; cobalto (cobalt), } 2 \mathrm{~g} \text {; } \\
\text { iodo (iodine), } 1 \mathrm{~g} \text {; e veículo qsp (vehicle qsp) 1000g. } \\
{ }^{3} \text { Salinomicina sódica (Sodic salinomicin)- } 60 \mathrm{ppm} \text {. } \\
{ }^{4} \text { Hidroxi-butil-tolueno. } \\
{ }^{5} 60 \% \text { mg de colina (60\% of choline). } \\
{ }^{6} \text { Virginiamicina } 2 \% \text { (Virginiamicin). }\end{array}$} \\
\hline
\end{tabular}

(Sistema para Análises Estatísticas), desenvolvido na Universidade Federal de Viçosa - UFV (1999). As estimativas das exigências de lisina digestível foram estabelecidas com base nos resultados de desempenho, por meio de modelos de regressão linear, quadrática e/ou descontínuo "Linear Response Plateau” (LRP), conforme o melhor ajuste obtido para cada variável. 
Tabela 3 - Composição em aminoácidos totais e digestíveis dos ingredientes das rações Table 3 - Composition in total and digestible amino acids of diet ingredients

\begin{tabular}{|c|c|c|c|c|c|c|}
\hline \multirow[t]{2}{*}{$(\%)$} & \multicolumn{2}{|c|}{$\begin{array}{c}\text { Milho } \\
\text { Corn }\end{array}$} & \multicolumn{2}{|c|}{$\begin{array}{c}\text { Farelo de soja } \\
\text { Soybean meal }\end{array}$} & \multicolumn{2}{|c|}{$\begin{array}{c}\text { Glúten de milho } \\
\text { Corn gluten }\end{array}$} \\
\hline & $\begin{array}{l}\mathrm{AAT}^{1} \\
\mathrm{TAA}^{1}\end{array}$ & $\begin{array}{l}\mathrm{AAD}^{2} \\
\mathrm{DAA}^{2}\end{array}$ & $\begin{array}{l}\mathrm{AAT}^{1} \\
\mathrm{TAA}^{1}\end{array}$ & $\begin{array}{l}\mathrm{AAD}^{2} \\
\mathrm{DAA}^{2}\end{array}$ & $\begin{array}{l}\mathrm{AAT}^{1} \\
\mathrm{TAA}^{1}\end{array}$ & $\begin{array}{l}\mathrm{AAD}^{2} \\
\mathrm{DAA}^{2}\end{array}$ \\
\hline Lisina (Lysine) & 0,2730 & 0,2239 & 2,9634 & 2,6374 & 1,0558 & 1,0030 \\
\hline Metionina (Methionine) & 0,1588 & 0,1477 & 0,4300 & 0,3913 & 1,4552 & 1,3970 \\
\hline Met+cis $($ Meth + Cys $)$ & 0,3213 & 0,2809 & 1,0404 & 0,9045 & 2,2027 & 2,0922 \\
\hline Arginina (Arginine) & 0,2919 & 0,2715 & 3,4906 & 3,2812 & 2,2243 & 2,2021 \\
\hline Valina (Valine) & 0,3749 & 0,3337 & 2,1104 & 1,8571 & 3,0156 & 2,9553 \\
\hline Glicina + Serina (Glycine+ser) & 0,6117 & 0,5312 & 4,4794 & 3,9525 & 4,6493 & 4,3833 \\
\hline Triptofano (Thryptophan) & 0,0628 & 0,0565 & 0,4354 & 0,3657 & 0,5370 & 0,5209 \\
\hline Leucina (Leucine) & 0,8913 & 0,8467 & 3,6415 & 3,2773 & 11,0267 & 10,8062 \\
\hline Prolina (Proline) & 0,7504 & - & 2,6615 & - & 6,9537 & - \\
\hline Proteína bruta (Crude protein) & \multicolumn{2}{|c|}{8,35} & \multicolumn{2}{|c|}{46,81} & \multicolumn{2}{|c|}{61,77} \\
\hline
\end{tabular}

Ensaio 2 - Níveis de lisina digestível em rações, mantendo-se a relação aminoacídica, para frangos de corte de 1 a 21 dias de idade, criados em ambiente de termoneutralidade

Foram utilizados 320 frangos de corte machos Avian Farms na fase de 1 a 21 dias de idade, com peso inicial de 47,8 g \pm 0,18 g, vacinados contra as doenças de Marek e Bouba aviária, em câmaras climáticas, sob temperatura e umidade relativa recomendados no manual Avian Farms (Tabela 1). As aves foram distribuídas em delineamento inteiramente casualizado, com quatro tratamentos, oito repetições e dez aves por repetição.

A ração basal (Tabela 4), à base de milho, farelo de soja e glúten de milho, foi formulada para atender as exigências das aves, segundo recomendações de Rostagno et al. (1996), e suplementada com L-lisina 99\%, resultando em rações experimentais contendo 1,16 e $1,04 \% ; 1,22$ e $1,10 \% ; 1,28$ e $1,16 \% ; 1,34$ e $1,22 \%$ de lisina total e digestível, respectivamente. As concentrações dos aminoácidos DL-metionina, L-treonina, triptofano, L-valina, L-isoleucina earginina, em relação à lisina, foram mantidas em quantidades suficientes para se obter o padrão de proteína ideal, conforme preconizado por Baker \& Han (1994) para aminoácidos digestíveis, em que lisina equivale a $100 \%$, metionina + cistina, a $72 \%$, treonina, a $67 \%$, triptofano, a $16 \%$, valina, a $77 \%$, isoleucina, a $67 \%$ e arginina, a 105\%. Os valores dos aminoácidos totais dos ingredientes das rações experimentais foram obtidos por meio de análises laboratoriais, e foram, posteriormente corrigidos para aminoácidos digestíveis, utilizando-se os coeficientes de digestibilidade das tabelas Rhodimet-RhônePoulenc (1993) (Tabela 3). O fornecimento de ração e água foi ad libitum, trocando-se a água duas vezes ao dia.

Os procedimentos de monitoramento do ambiente e do fornecimento de ração, a determinação das medidas de desempenho e de rendimento de carcaça, a análise e o modelo estatístico foram os mesmos utilizados no ensaio 1.

\section{Resultados e Discussão}

Os resultados de desempenho e de consumo de lisina digestível dos pintos de corte na fase de 1 a 21 dias de idade, alimentados com rações contendo diferentes níveis de lisina digestível, mantendo-se ou não a relação aminoacídica e mantidos em ambiente termoneutro são apresentados na Tabela 5. 
Tabela 4 - Composição percentual das rações experimentais

Table 4 - Composition (\%) of the experimental diets

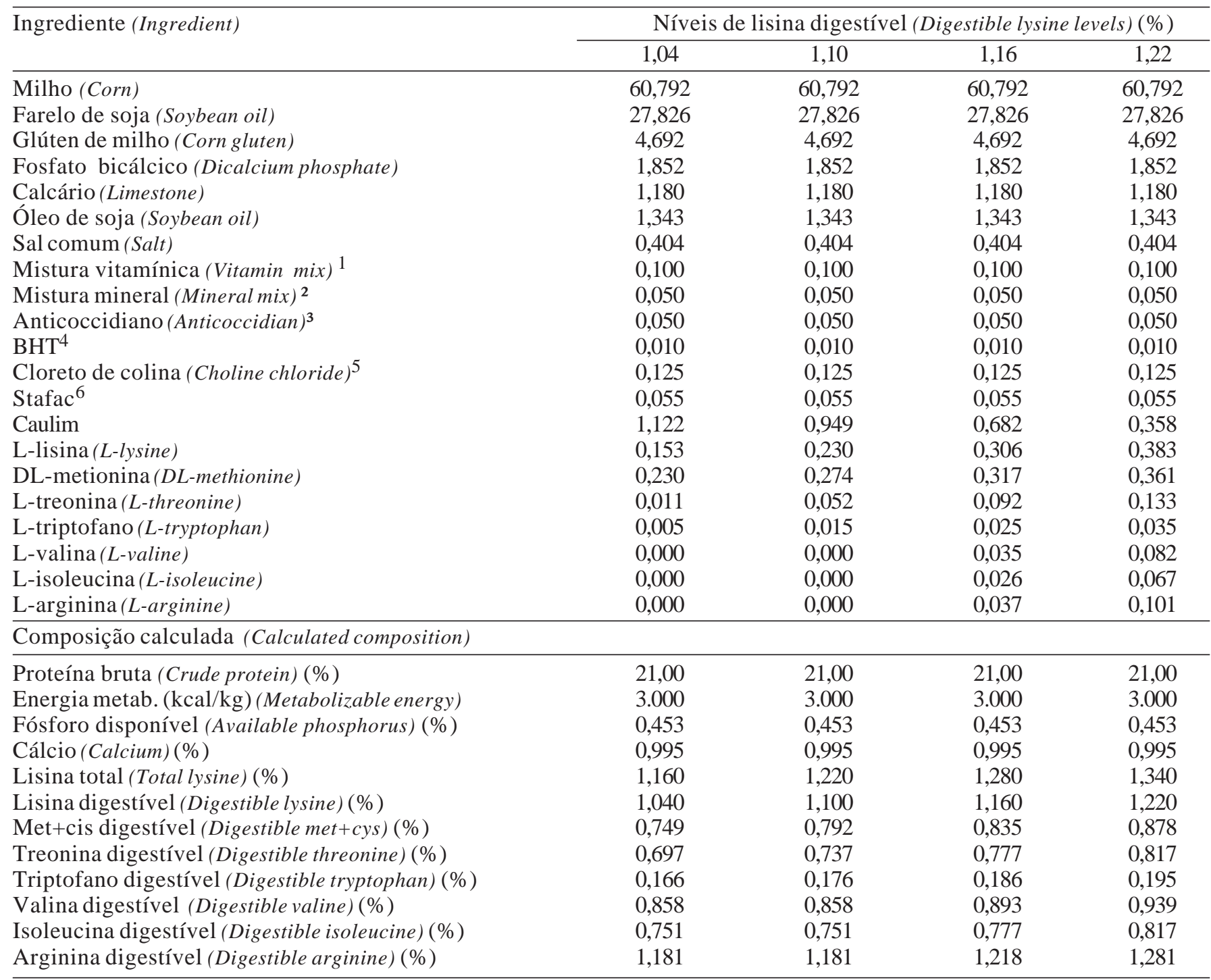

${ }^{1}$ Conteúdo/kg (Content/kg) - vit. A - 15.000.000 UI, vit. D3 - 1.500.000 UI, vit. E - 15.000 UI, vit. B1 - 2,0 g, vit. B2 - 4,0 g, vit. B6 - 3,0 g, vit. B12 - 0,015 g, ácido nicotínico (nicotinic acid) - $25 \mathrm{~g}$, ácido pantotênico (pantothenic acid) - $10 \mathrm{~g}$, vit. K3 - 3,0 g, ácido fólico (pholic acid) - $1,0 \mathrm{~g}$, bacitracina de zinco (zinc bacitracin) - $10 \mathrm{~g}$, selênio (selenium) - $250 \mathrm{mg}$ e veículo (and vehicle) qsp - $1.000 \mathrm{~g}$.

${ }^{2}$ Conteúdo/kg (Content/kg) - Mn, 80g; Fe, 80 g; Zn, 50g; Cu, 10 g; Co, 2 g; I, 1 g; e veículo (and vehicle) qsp 1000g.

3 Salinomicina sódica - 60 ppm. (Sodium salinomicin).

4 Hidroxi-butil-tolueno.

$560 \%$ de colina (60\% of choline).

${ }^{6}$ Virginiamicina $2 \%$ (Virginiamicin).

Verificou-se efeito linear $(\mathrm{P}<0,05)$ dos níveis de lisina digestível sobre o peso das aves aos 21 dias de idade (Figura 1), quando se utilizaram as rações mantendo a relação entre a lisina e os demais aminoácidos essenciais considerados críticos para as aves. No entanto, o modelo "Linear Response Plateau" - LRP foi o que melhor se ajustou aos dados, estimando em $1,17 \%$ de lisina digestível o nível a partir do qual os dados permaneceram em um plateau. Quando foram usadas as rações convencionais, sem correção do perfil aminoacídico, o peso das aves aos 21 dias aumentou $(\mathrm{P}<0,01)$ de forma quadrática até o nível estimado de $1,13 \%$ de lisina digestível, correspondente a $1,25 \%$ de lisina total (Figura 2).

Constatou-se aumento $(\mathrm{P}<0,01)$ quadrático no ganho de peso até o nível de 1,13\% de lisina digestível quando se utilizou a ração convencional elinear $(\mathrm{P}<0,05)$ quando se utilizou a ração com correção do balanço aminoacídico. Apesar da variação linear, a melhor resposta de ganho de peso foi obtida no nível de 1,17\% de lisina digestível, estimado por meio do modelo LRP, que melhor se ajustou aos dados (Figuras 3 e 4). 
Tabela 5 - Efeito dos níveis de lisina digestível na ração, mantendo ou não a relação aminoacídica, sobre o desempenho de pintos de corte no período de 1 a 21 dias de idade, mantidos em condições de termoneuttralidade

Table 5 - Effect of dietary levels of digestible lysine, maintaining or not the amino acid relation, on performance of broilers from 1 to 21 days old on thermoneutral environment

\begin{tabular}{|c|c|c|c|c|c|c|c|c|c|c|c|}
\hline \multirow{3}{*}{$\begin{array}{l}\text { Variável } \\
\text { Variable }\end{array}$} & \multicolumn{11}{|c|}{ Níveis de lisina digestível (Digestible lysine levels) (\%) } \\
\hline & \multicolumn{6}{|c|}{$\begin{array}{l}\text { Ração convencional } \\
\text { Conventional diet }\end{array}$} & \multicolumn{5}{|c|}{$\begin{array}{l}\text { Ração mantendo relação aminoacídica } \\
\text { Diet maintaining the amino acid relation }\end{array}$} \\
\hline & 0,92 & 0,98 & 1,04 & 1,10 & 1,16 & $\mathrm{CV}$ & 1,04 & 1,10 & 1,16 & 1,22 & $\mathrm{CV}$ \\
\hline $\begin{array}{l}\text { Peso aos } 21 \text { dias (g) } \\
\text { Body weight at } 21 \text { days }\end{array}$ & $560^{\mathrm{Q}}$ & 635 & 676 & 698 & 701 & 3,07 & $676^{\mathrm{L} 2}$ & 687 & 705 & 706 & 3,74 \\
\hline $\begin{array}{l}\text { Ganho de peso }(\mathrm{g})^{1} \\
\text { Body weight } \text { gain }^{1}\end{array}$ & $512^{Q}$ & 587 & 630 & 650 & 653 & 3,31 & $630^{\mathrm{L} 2}$ & 639 & 657 & 658 & 4,00 \\
\hline $\begin{array}{l}\text { Consumo de ração (g) } \\
\text { Feed intake }\end{array}$ & $812^{\mathrm{Q}}$ & 892 & 917 & 936 & 936 & 3,05 & 917 & 930 & 930 & 927 & 2,36 \\
\hline $\begin{array}{l}\text { Consumo lisina digestível }(\mathrm{g})^{1} \\
\text { Digestible lysine intake }\end{array}$ & $7,5^{\mathrm{L} 1}$ & 8,7 & 9,5 & 10,3 & 10,8 & 2,94 & $9,5^{\mathrm{L} 1}$ & 10,2 & 10,8 & 11,3 & 2,3 \\
\hline $\begin{array}{l}\text { Conversão alimentar } \\
\text { Feed:gain ratio }\end{array}$ & $1,59 \mathrm{Q}$ & 1,52 & 1,46 & 1,44 & 1,43 & 3,03 & 1,46 & 1,46 & 1,42 & 1,41 & 4,53 \\
\hline
\end{tabular}

L1, L2 Efeito linear $(P<0,01)$ e $(P<0,05)$, respectivamente (Linear effect, $P<0.01$ and $P<0.05$, respectively).

$Q$ Efeito quadrático $(P<0,01)$ (Quadratic effect, $P<0.01)$.

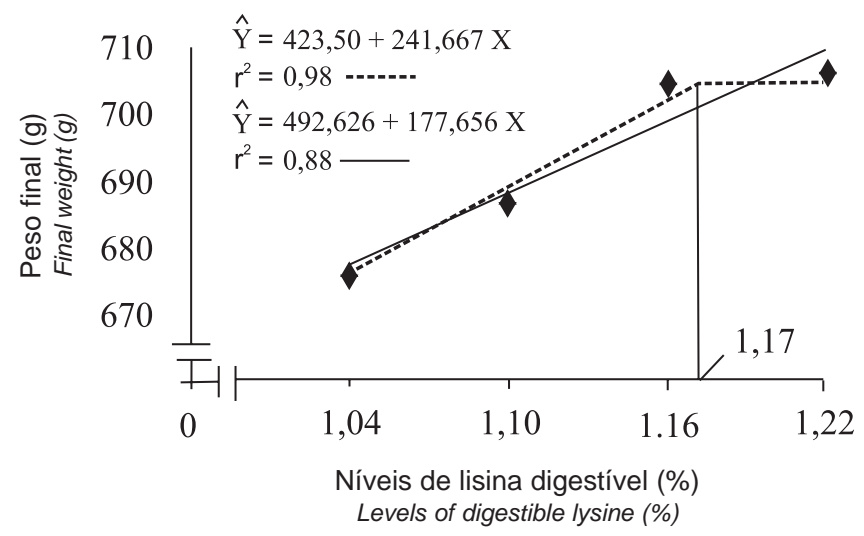

Figura 1 - Efeito dos níveis de lisina da ração, mantendo a relação aminoacídica, sobre o peso dos frangos de corte de 1 a 21 dias de idade, criados em ambiente de termoneutralidade.

Figure 1 - Effect of dietary lysine levels, maintaining the amino acid relation, on final weight of broilers from 1 to 21 days old on thermoneutral environment.

Estes resultados estão coerentes com aqueles obtidos por Conhalato et al. (1999), Costa et al. (1999) e Barboza et al. (2000), que observaram variação quadrática no ganho de peso das aves, em razão do aumento do nível de lisina em ração convencional, e por Cella et al. (2000) e Conhalato et al. (2000), que verificaram aumento linear do ganho de peso com a elevação do nível de lisina em rações com correção do balanço aminoacídico, em experimentos conduzidos ambiente de termoneutralidade.

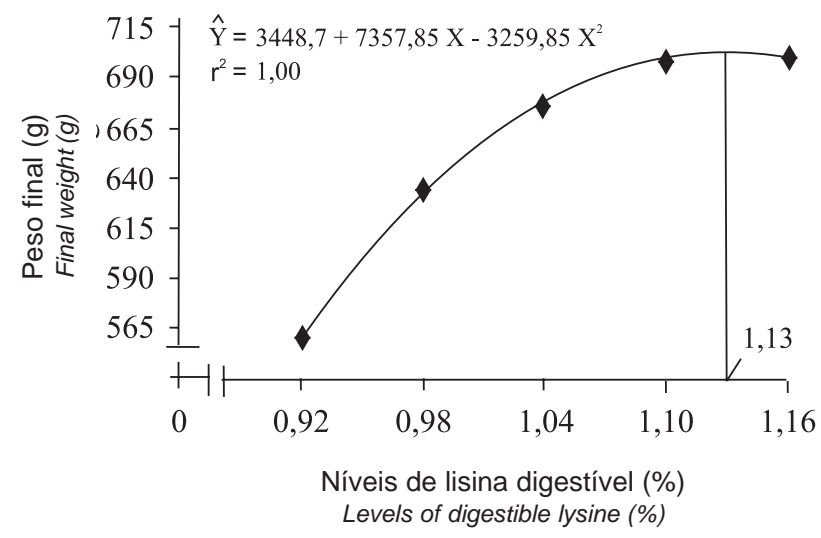

Figura 2 - Efeito dos níveis de lisina da ração convencional sobre o peso final dos frangos de corte de 1 a 21 dias de idade, criados em ambiente de termoneutralidade.

Figure 2 - Effect of lysine levels in conventional diet on final weight of broilers from 1 to 21 days old on thermoneutral environment.

Apesar da pequena variação no ganho de peso das aves, o nível de 1,13\% de lisina digestível, que proporcionou o maior ganho quando se utilizou a ração convencional, ficou entre os níveis de 1,05 e 1,17\%, obtidos por Conhalato et al. (1999) e Costa etal. (1999), respectivamente. O nível de $1,17 \%$, que refletiu em melhor resposta de ganho de peso com as rações mantendo-se o balanço aminoacídico, ficou abaixo dos níveis de 1,20 e 1,293\% encontrados por Conhalato et al. (2000) e Cella et al. (2000), espectivamente. 


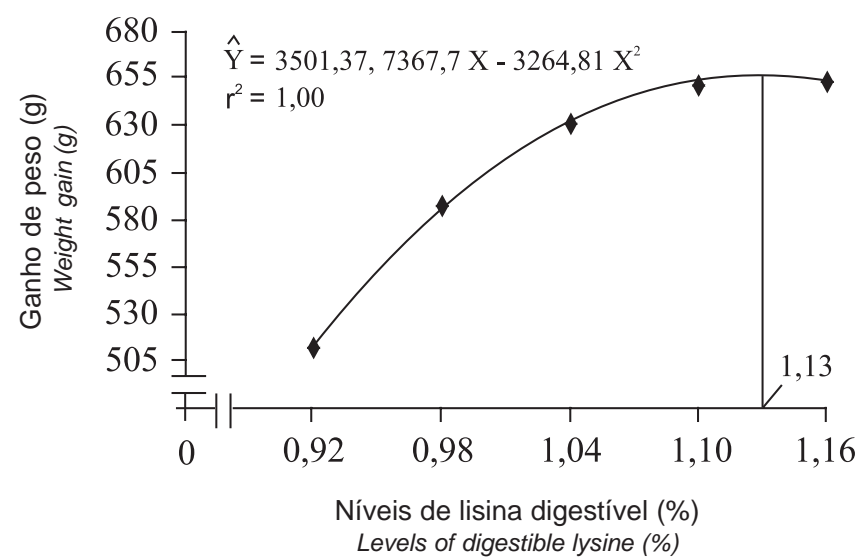

Figura 3 - Efeito dos níveis de lisina da ração convencional sobre o ganho de peso de frangos de corte de 1 a 21 dias de idade, criados em ambiente de termoneutralidade.

Figure 3 - Effect of lysine levels in conventional diet on weight gain of broilers from 1 to 21 days old on thermoneutral environment.

O consumo de ração das aves que receberam a ração convencional aumentou $(\mathrm{P}<0,01)$ de forma quadrática até o nível de 1,11\% de lisina (Figura 5), enquanto o das aves alimentadas com rações em que se considerou a relação aminoacídica não variou $(\mathrm{P}>0,05)$ entre os tratamentos. Resultados similares aos deste trabalho foram obtidos por Han \& Baker (1993), Knowler \& Southern (1998) e Costa et al. (1999), utilizando ração convencional, e por Conhalato et al. (2000) e Cella et al. (2000), que trabalharam com rações elaboradas considerando-se o conceito da proteína ideal.

Com base nos resultados de consumo, pode-se deduzir que a diferença de resposta observada quando se utilizou a ração convencional ou não, ocorreu em razão dos dois menores níveis de lisina avaliados quando se utilizou a ração convencional (0,92 e 0,98\%), de modo que a possível deficiência de lisina e o conseqüente desbalanço de aminoácidos das rações influenciaram negativamente o consumo das aves. De acordo com Parr \& Summers (1991), além da energia, o desequilíbrio entre os aminoácidos exerce influência significativa sobre a ingestão de alimentos.

Os níveis de lisina das rações, mantendo ou não a relação entre a lisina e os demais aminoácidos essenciais, influenciaram $(\mathrm{P}<0,01)$ o consumo de lisina digestível dos pintos de corte, que aumentou linearmente, de acordo com as equações $\hat{\mathrm{Y}}=-5,02758+$ $13,8528 X\left(r^{2}=0,98\right)$, quando se utilizou a ração

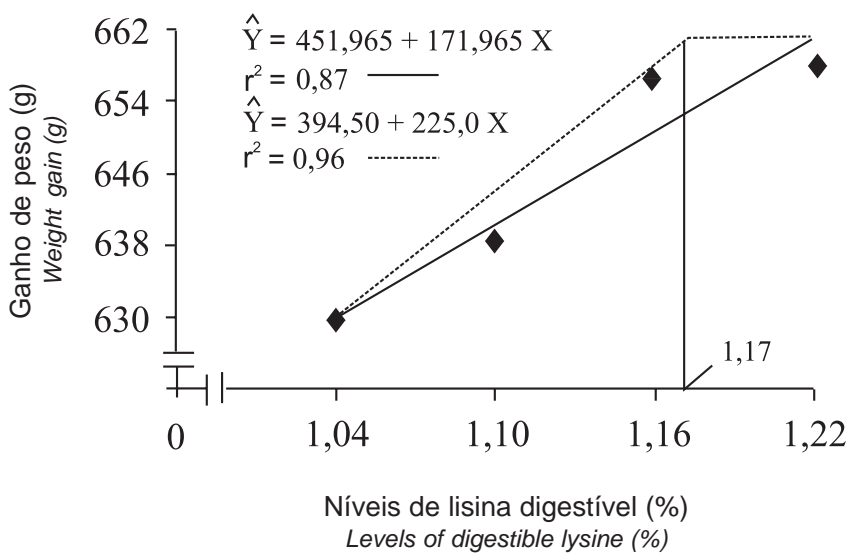

Figura 4 - Efeito dos níveis de lisina da ração, mantendo a relação aminoacídica, sobre o ganho de peso de frangos de corte de 1 a 21 dias de idade, criados em ambiente de termoneutralidade.

Figure 4 - Effect of dietary lysine levels, maintaining the amino acid relation, on weight gain of broilers from 1 to 21 days old on thermoneutral environment.

convencional e $\hat{\mathrm{Y}}=-0,620108+9,80980 \mathrm{X}\left(\mathrm{r}^{2}=0,95\right)$, quando se considerou a relação aminoacídica. Resultados semelhantes foram obtidos por Conhalato et al. (1999, 2000), e Cella et al. (2000), que também observaram variação no consumo de lisina em razão de sua concentração na ração.

Enquanto a conversão alimentar das aves que receberam ração convencional reduziu $(\mathrm{P}<0,01)$ de forma quadrática até o nível de 1,14\% de lisina (Figura 6), a conversão alimentar daquelas que receberam ração com correção do balanço aminoacídico não variou $(\mathrm{P}>0,10)$ entre os tratamentos. Variação na conversão alimentar de aves na fase inicial em razão da concentração da lisina na ração convencional, também foi observada por Han \& Baker (1991, 1993).

Conhalato et al. (1999), Costa et al. (1999) e Barboza et al. (2000). Ainda, de forma similar a este trabalho, Cella et al. (2000) e Conhalato et al. (1999) não observaram variação na conversão alimentar das aves com o aumento do nível de lisina da ração em que se corrigiu o balanço aminoacídico.

Considerando-se que a lisina é um dos aminoácidos essenciais e é preferencialmente utilizada para deposição de proteína na carcaça (Baker, 1991), os piores valores de ganho de peso e conversão alimentar observados com os dois menores níveis de lisina avaliados em rações convencionais permitem inferir que a lisina foi o primeiro aminoácido limitante nestas rações. 


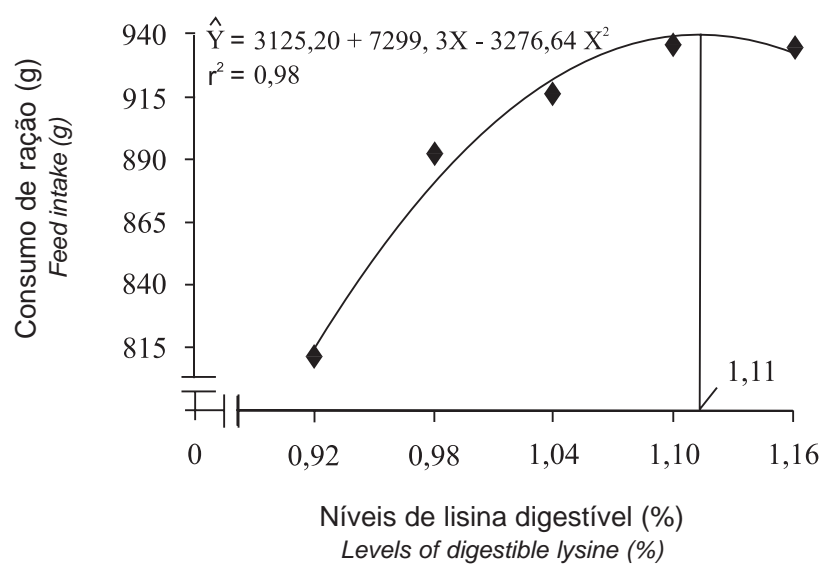

Figura 5 - Efeito dos níveis de lisina da ração convencional sobre o consumo de ração de frangos de corte de 1 a 21 dias de idade, criados em ambiente de termoneutralidade.

Figure 5 - Effect of lysine levels in conventional diet on feed intake of broilers from 1 to 21 days old on thermoneutral environment.

Com base na análise dos resultados de desempenho, em que os valores absolutos de ganho de peso e conversão alimentar observados nos três níveis de lisina comuns $(1,04 ; 1,10$ e 1,16\%) aos dois tipos de rações praticamente não variaram, pode-se deduzir que as aves expressaram o seu máximo potencial de eficiência de crescimento no nível de 1,13\% de lisina digestível. Assim, não se obteve resposta positiva ao se corrigir o balanço de aminoácidos a partir deste nível.

Os resultados de pesos absoluto e relativo da carcaça e dos órgãos (comestíveis e não-comestíveis) dos frangos de corte aos 21 dias de idade estão apresentados na Tabela 6 .

Os níveis de lisina das rações convencionais influenciaram $(\mathrm{P}<0,01)$ de forma quadrática o peso absoluto da carcaça, que elevou até o nível de 1,13\% (Figura 7), e de forma linear crescente $(\mathrm{P}<0,05)$ o peso relativo de carcaça, segundo a equação: $\hat{\mathrm{Y}}=61,8716+10,5894 \mathrm{X} \quad\left(\mathrm{r}^{2}=0,91\right)$. Quando se corrigiu o balanço aminoacídico das rações, o peso absoluto da carcaça aumentou de forma linear $(\mathrm{P}<0,01)$, enquanto o peso relativo da carcaça não variou com os tratamentos.

A resposta de peso relativo de carcaça obtida com a ração convencional nos níveis de 0,92 e 0,98\% de lisina digestível corrobora o relato anterior de que estes níveis ficaram aquém da exigência dos animais, restringindo, conseqüentemente, o seu crescimento.

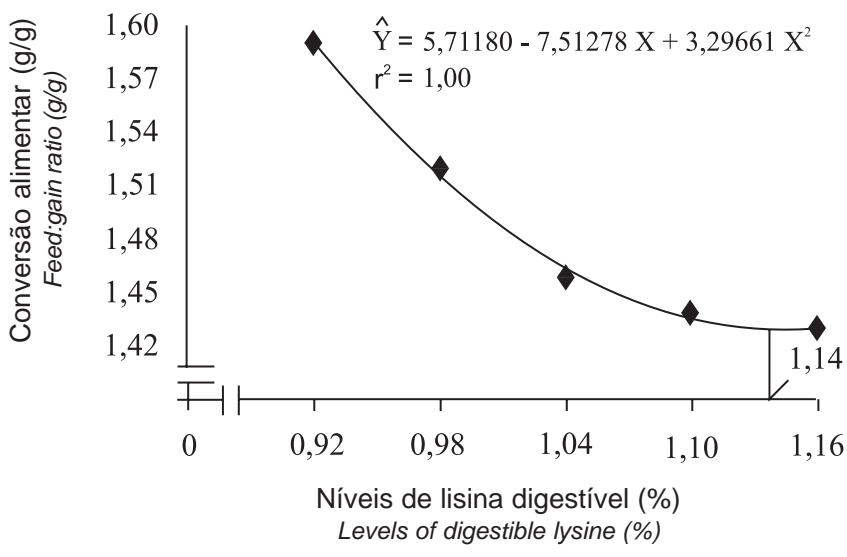

Figura 6 - Efeito dos níveis de lisina da ração convencional sobre a conversão alimentar de frangos de corte de 1 a 21 dias de idade, criados em ambiente de termoneutralidade.

Figure 6 - Effect of lysine levels in conventional diet on feed:gain ratio of broilers from 1 to 21 days old on thermoneutral environment.

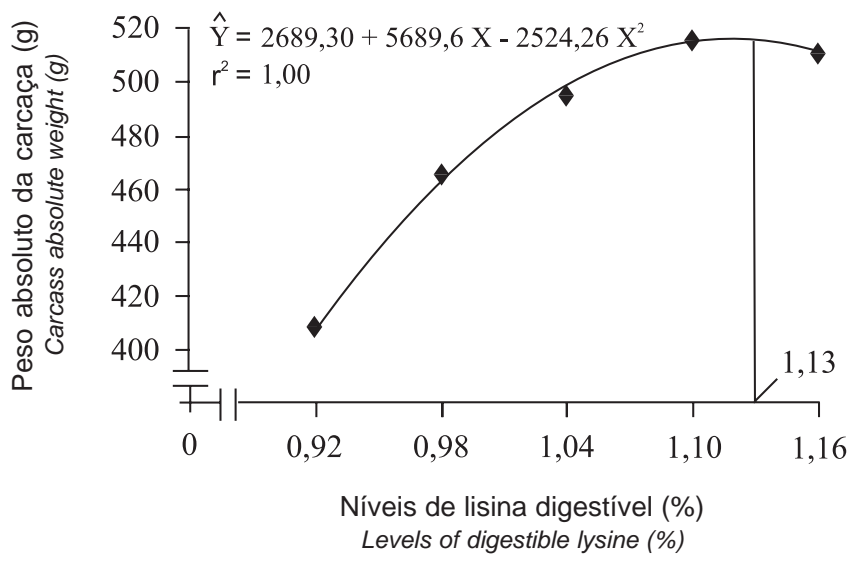

Figura 7 - Efeito dos níveis de lisina da ração convencional sobre o peso absoluto da carcaça dos pintos de corte, mantidos em ambiente termoneutro.

Figure 7 - Effect of lysine levels in conventional diet on carcass absolute weight gain of broilers from 1 to 21 days of old on thermoneutral environment.

Os tratamentos influenciaram $(\mathrm{P}<0,05)$ o peso absoluto da moela, que elevou linearmente segundo a equação: $\hat{Y}=6,63250+7,08631 X\left(r^{2}=0,96\right)$, e os pesos relativos do coração $(\mathrm{P}<0,05)$ e do intestino $(\mathrm{P}<0,05)$, que reduziram de forma linear com os níveis de lisina da ração, segundo as equações: $\hat{Y}=1,25981$ - 0,402598X $\left(\mathrm{r}^{2}=0,71\right)$ e $\hat{\mathrm{Y}}=6,6209-2,31084 \mathrm{X}$ 
Tabela 6 - Valores de pesos absolutos e relativos da carcaça, dos órgãos comestíveis (coração, fígado e moela) e nãocomestíveis (intestinos) das aves aos 21 dias, mantidas sob conforto térmico, recebendo rações com diferentes níveis de lisina, mantendo ou não a relação aminoacídica

Table 6 - Values of absolute and relative weights of carcass, of edible organs (heart, liver and gizzard) and non edible (guts) for broilers at 21 days old on thermoneutral environment fed diets with different lysine levels, maintaining or not the amino acid relation

\begin{tabular}{|c|c|c|c|c|c|c|c|c|c|c|c|}
\hline \multirow{3}{*}{$\begin{array}{l}\text { Variável } \\
\text { Variable }\end{array}$} & \multicolumn{11}{|c|}{ Níveis de lisina digestível (Digestible lysine levels) (\%) } \\
\hline & \multicolumn{6}{|c|}{$\begin{array}{l}\text { Ração convencional } \\
\text { Conventional diet }\end{array}$} & \multicolumn{5}{|c|}{$\begin{array}{l}\text { Ração mantendo relação aminoacídica } \\
\text { Diet maintaining the amino acid relation }\end{array}$} \\
\hline & 0,92 & 0,98 & 1,04 & 1,10 & 1,16 & $\mathrm{CV}$ & 1,04 & 1,10 & 1,16 & 1,22 & $\mathrm{CV}$ \\
\hline \multicolumn{12}{|l|}{ Peso absoluto (g) } \\
\hline \multicolumn{12}{|l|}{ Absolute weight } \\
\hline Carcaça (Carcass) & $407^{Q}$ & 466 & 495 & 516 & 511 & 6,41 & $495^{\mathrm{L} 1}$ & 509 & 513 & 534 & 6,01 \\
\hline Coração (Heart) & 3,75 & 3,87 & 4,07 & 4,13 & 4,12 & 19,09 & 4,07 & 3,87 & 4,14 & 4,27 & 17,88 \\
\hline Fígado (Liver) & 12,94 & 13,25 & 15,06 & 15,27 & 14,62 & 15,46 & 15,06 & 15,19 & 14,87 & 16,19 & 12,35 \\
\hline Moela (Guizzard) & $12,56^{\mathrm{L} 2}$ & 12,37 & 13,94 & 14,00 & 14,44 & 16,49 & 13,94 & 14,62 & 14,80 & 15,31 & 14,37 \\
\hline Intestinos (Gut) & 18,50 & 19,06 & 20,50 & 21,93 & 19,37 & 18,37 & 20,50 & 21,00 & 18,93 & 20,25 & 18,19 \\
\hline \multicolumn{12}{|l|}{ Peso relativo (\%) } \\
\hline \multicolumn{12}{|l|}{ Relative weight } \\
\hline Carcaça (Carcass) & $75,32^{\mathrm{L} 2}$ & 76,70 & 77,09 & 77,38 & 77,98 & 1,68 & 77,09 & 76,95 & 77,73 & 77,50 & 1,62 \\
\hline Coração (Heart) & $0,93^{\mathrm{L} 2}$ & 0,83 & 0,82 & 0,80 & 0,81 & 18,75 & 0,82 & 0,77 & 0,81 & 0,80 & 18,21 \\
\hline Fígado (Liver) & 3,21 & 2,86 & 3,04 & 2,95 & 2,86 & 16,28 & 3,04 & 2,98 & 2,89 & 3,03 & 11,06 \\
\hline Moela (Guizzard) & 3,09 & 2,67 & 2,82 & 2,71 & 2,83 & 16,13 & 2,82 & 2,88 & 2,88 & 2,88 & 15,74 \\
\hline Intestinos (Gut) & $4,57^{\mathrm{L} 2}$ & 4,13 & 4,16 & 4,25 & 3,79 & 19,95 & 4,16 & 4,14 & 3,69 & 3,81 & 21,23 \\
\hline
\end{tabular}

L1, L2 Efeito linear $(P<0,01)$ e $(P<0,05)$, respectivamente (Linear effect, $P<0.01$ and $P<0.05$, respectively).

Q Efeito quadrático $(P<0,01)$ (Quadratic effect, $P<0.01)$.

$\left(r^{2}=0,67\right)$, respectivamente, quando se utilizou a ração convencional. Em contrapartida, não se observou variação $(\mathrm{P}>0,05)$ nos pesos absoluto e relativo das vísceras das aves que receberam as rações em que se considerou o balanço aminoacídico.

Os maiores valores dos pesos relativos do coração e do intestino, observados nos níveis de 0,92 e 0,98\% de lisina digestível das aves que receberam a ração convencional, são indicativos de que a deficiência de lisina é mais prejudicial à deposição de proteína na carcaça que ao desenvolvimento das vísceras. Segundo Reeds et al. (1993), quando leitões muito jovens consomem dietas inadequadas em proteína, mantêm significativas deposições de proteína no trato gastrintestinal, enquanto interrompem a deposição de proteína na musculatura esquelética.

\section{Conclusões}

Frangos de corte machos da linhagem Avian Farms no período de 1 a 21 dias de idade, mantidos em ambiente de termoneutralidade, exigem, no mínimo, 1,14e 1,17\% de lisina digestível na ração convencional e na ração mantendo a relação aminoacídica, respectivamente, correspondendo ao consumo estimado de 10,8 g.

\section{Literatura Citada}

AVIAN FARMS. Broiler manual. In: http://www.avianfarms.com Avian Farms International, Inc., 1998, 34p.

BAKER, D.H.; HAN, Y. Ideal amino acid profile for chickens during the first three weeks posthatching. Poultry Science, v.73, p.1441-1447, 1994.

BARBOZA, W.A.; ROSTAGNO, H.S.; ALBINO, L.F.T. et al. Níveis de lisina para frangos de corte de 1 a 21 e 15 a 40 dias de idade. Revista Brasileira de Zootecnia, v.29, p.1082-1090, 2000.

BARBOZA, W.A.; ROSTAGNO, H.S.; ALBINO, L.F.T. et al. Exigência nutricional de lisina digestível para frangos de corte. Revista Brasileira de Zootecnia, v.29, p.10981102, 2000a.

CELLA, P.S.; DONZELE, J.L.; OLIVEIRA, R.F.M. et al. Níveis de lisina mantendo a relação aminoacídica para frangos de corte no período de 1 a 21 dias de idade, em diferentes ambientes térmicos. Revista Brasileira de Zootecnia, v.30, p.433-439, 2001.

CONHALATO, G.S.; DONZELE, J.L.; OLIVEIRA, R.F.M. et al. Avaliação de rações contendo diferentes níveis de lisina digestível mantendo a relação aminoacídica para pintos de corte na fase de 1 a 21 dias de idade. Revista Brasileira de Zootecnia, v.26, p.2066-2071, (Supl. 1), 2000.

CONHALATO, G.S.; DONZELE, J.L.; ROSTAGNO, H.S. et al. Níveis de lisina digestível para frangos de corte machos na fase de 1 a 21 dias de idade. Revista Brasileira de Zootecnia, v.28, p.91-97, 1999.

COSTA, F.G.P.; ROSTAGNO, H.S.; ALBINO, L.F.T. et al. Níveis dietéticos de lisina para frangos de corte, no período de 1 a 21 
dias de idade. In: CONFERÊNCIA APINCO DE CIÊNCIA E TECNOLOGIA AVÍCOLAS, 1999, Campinas. Anais... Campinas: Fundação Apinco de Ciências e Tecnologias Avícolas, 1999. p.17.

EMMERT, M.W.; BAKER, D.H. Use of the ideal protein concept for presicion formulation of amino acid levels in broilers diets. Journal of Applied Poultry Research, v.6, p.462-470, 1997.

HAN, Y.; BAKER, D.H. Effects of sex, heat stress, body weight, and genetic strain on the dietary lysine requirement of broiler chicks. Poultry Science, v.72, p.701-708, 1993.

HAN, Y.; BAKER, D.H. Lysine requirementof fast and slow growing broiler chicks. Poultry Science, v.70, p.21082114, 1991.

KNOWLES, T.A.; SOUTHERN, L.L. The lysine requirement and ratio of total sulfur amino acids to lysine for chicks fed adequate or inadequate lysine. Poultry Science, v.77, p.564-569, 1998.

PACK, M. Proteína ideal para frangos de corte. Conceitos e posição atual. In: CONFERÊNCIA APINCO DE CIÊNCIA E TECNOLOGIA AVÍCOLAS, 1995, Curitiba. Anais... Curitiba: Fundação Apinco de Ciências e Tecnologias Avícolas, 1995. p.95-110.

PARR, J.F.; SUMMERS, J.D. The effects of minimizing amino acid excess in broiler diets. Poultry Science, v.70, p.15401549, 1991.

REEDS, P.J.; BURRIN, D.G.; DAVIS, T.A. et al. Growth the regulation with particular reference to the pig. In: HOLLIS,
G.R. (Ed.) Growth of the pig. Wallingford: CAB International, 1993. p.1-32.

RHODIMET feed formulation guide. 6.ed. France: Rhône-Poulenc Animal Nutrition, 1993. 39p.

ROSTAGNO, H.S.; ALBINO, L.F.T.; DONZELE, J.L. et al. Tabelas brasileiras para aves e suínos. Composição de alimentos e exigências nutricionais. Viçosa, MG: Universidade Federal de Viçosa, 2000. 141p.

ROSTAGNO, H.S.; BARBARINO JR., P.; BARBOZA, W.A. Exigências nutricionais das aves determinadas no Brasil. In: SIMPÓSIO INTERNACIONAL SOBRE EXIGÊNCIAS NUTRICIONAIS DE AVES E SUÍNOS, 1996, Viçosa, MG. Anais... Viçosa, MG: Universidade Federal de Viçosa, 1996. p.361.

SURISDIARTO, A.; FARREL, D.J. The relationship between dietary crude protein and dietary lysine requirement by broiler chicks on diets with and without the "ideal" amino acids balance. Poultry Science, v.70, p.830-836, 1991.

UNIVERSIDADE FEDERAL DE VIÇOSA - UFV. Manual de Utilização do Programa SAEG (Sistema para Análises Estatísticas 8.0). Viçosa, MG: UFV, 1999. 141p.

ZAVIEZO, D. Proteína ideal - Novo conceito nutricional da formulação de rações para aves e suínos. Avicultura Industrial, p.16-18, 1998.

Recebido em: $17 / 08 / 04$

Aceito em: 28/02/05 